\title{
Oral contraceptives, reproductive history and risk of colorectal cancer in the European Prospective Investigation into Cancer and Nutrition
}

\begin{abstract}
KK Tsilidis*, , NE Allen', TJ Key', K Bakken², E Lund ${ }^{2}$, F Berrino ${ }^{3}$, A Fournier ${ }^{4,5}$, A Olsen ${ }^{6}$, A Tjønneland ${ }^{6}$, K Overvad $^{7}$, M-C Boutron-Ruault ${ }^{4,5}$, F Clavel-Chapelon, ${ }^{4,5}$, G Byrnes ${ }^{8}$, V Chajes ${ }^{8}$, S Rinaldi ${ }^{8}$, J Chang-Claude', R Kaaks', M Bergmann $^{10}$, H Boeing ${ }^{10}$, Y Koumantaki ${ }^{11}$, G Stasinopoulou ${ }^{11,12}$, A Trichopoulou ${ }^{11,12}$, D Palli ${ }^{13}$, G Tagliabue $^{14}$, S Panico' ${ }^{15}$, R Tumino ${ }^{16}$, P Vineis ${ }^{17,18}$, HB Bueno-de-Mesquita ${ }^{19,20}$, FJB van Duijnhoven ${ }^{19}$, CH van Gils' ${ }^{21}$, PHM Peeters ${ }^{21}$, L Rodríguez ${ }^{22}$, CA González ${ }^{23}$, M-J Sánchez ${ }^{24}$, M-D Chirlaque ${ }^{25}$, A Barricarte ${ }^{26}$, M Dorronsoro ${ }^{27}$, S Borgquist ${ }^{28}$, J Manjer ${ }^{29}$, B van Guelpen ${ }^{30}$, G Hallmans ${ }^{31}$, SA Rodwell ${ }^{32,4}$, K-T Khaw ${ }^{33}$, T Norat $^{18}$, D Romaguera ${ }^{18}$ and E Riboli ${ }^{18}$
\end{abstract}

'Cancer Epidemiology Unit, Nuffield Department of Clinical Medicine, University of Oxford, Richard Doll Building, Roosevelt Drive, OX3 7LF Oxford, UK; ${ }^{2}$ Department of Community Medicine, University of Tromsø, Tromsø, Nonway; ${ }^{3}$ Department of Preventive and Predictive Medicine, National Cancer Institute, Milan, Italy; ${ }^{4}$ Inserm, Centre for Research in Epidemiology and Population Health, U I0I8, Institut Gustave Roussy, F-94805, Villejuif, France; ${ }^{5}$ Paris South University, UMRS 1018, F-94805, Villejuif, France; 'Institute of Cancer Epidemiology, Danish Cancer Society, Copenhagen, Denmark; ${ }^{7}$ Department of Epidemiology, School of Public Health, Aarhus University, Aarhus, Denmark; International Agency for Research on Cancer, Lyon, France; ${ }^{9}$ Division of Cancer Epidemiology, German Cancer Research Center, Heidelberg, Germany; ${ }^{10}$ Department of Epidemiology, German Institute of Human Nutrition, Potsdam, Germany; "Department of Hygiene and Epidemiology, University of Athens Medical School, Athens, Greece; ${ }^{12}$ Hellenic Health Foundation, Athens, Greece; ${ }^{13}$ Molecular and Nutritional Epidemiology Unit, Cancer Research and Prevention Institute, Florence, Italy; ${ }^{14}$ Environmental Epidemiology and Cancer Registry Unit, National Cancer Institute, Milan, Italy; ${ }^{15}$ Department of Clinical and Experimental Medicine, Federico II University, Naples, Italy; ${ }^{16}$ Cancer Registry and Histopathology Unit, Department of Oncology, Azienda Ospedaliera 'Civile - MP Arezzo', Ragusa, Italy; ${ }^{17}$ ISI Foundation, Torino, Italy; ${ }^{18}$ Department of Epidemiology and Biostatistics, School of Public Health, Imperial College, London, UK; ${ }^{19}$ National Institute for Public Health and the Environment, Bilthoven, The Netherlands; ${ }^{20}$ Department of Gastroenterology and Hepatology, University Medical Centre Utrecht, Utrecht, The Netherlands; ${ }^{21}$ Julius Center for Health Sciences and Primary Care, University Medical Center Utrecht, Utrecht, The Netherlands; ${ }^{22}$ Public Health and Participation Directorate, Health and Health Care Services Council, Asturias, Spain; ${ }^{23}$ Unit of Nutrition, Environment and Cancer, Cancer Epidemiology Research Programme, Catalan Institute of Oncology, Barcelona, Spain; ${ }^{24}$ Andalusian School of Public Health and CIBER de Epidemiología y Salud Pública, Granada, Spain; ${ }^{25}$ Department of Epidemiology, Regional Health Authority and CIBER de Epidemiología y Salud Pública, Murcia, Spain; ${ }^{26}$ Public Health Institute of Navarra, Pamplona, Spain; ${ }^{27}$ Public Health Division of Gipuzkoa and CIBER de Epidemiología y Salud Pública, San Sebastian, Spain; ${ }^{28}$ Department of Oncology, Lund University Hospital, Lund, Sweden; ${ }^{29}$ Department of Surgery, Malmö University Hospital, Malmö, Sweden;

${ }^{30}$ Department of Medical Biosciences, Pathology, Umeå University, Umeå, Sweden; ${ }^{31}$ Department of Public Health and Clinical Medicine, Nutritional Research, Umeå University, Umeå, Sweden; ${ }^{32}$ Medical Research Council Dunn Human Nutrition Unit, University of Cambridge, Cambridge, UK; ${ }^{33}$ Clinical Gerontology Unit, University of Cambridge, Cambridge, UK

BACKGROUND: Oral contraceptive use and reproductive factors may initiate long-term changes to the hormonal milieu and thereby, possibly influence colorectal cancer risk.

METHODS: We examined the association of hormonal and reproductive factors with risk of colorectal cancer among 337802 women in the European Prospective Investigation into Cancer and Nutrition, of whom 1878 developed colorectal cancer.

RESULTS: After stratification for center and age, and adjustment for body mass index, smoking, diabetes mellitus, physical activity and alcohol consumption, ever use of oral contraceptives was marginally inversely associated with colorectal cancer risk (hazard ratio $(H R), 0.92 ; 95 \%$ confidence interval $(\mathrm{Cl}), 0.83-1.02)$, although this association was stronger among post-menopausal women $(\mathrm{HR}, 0.84 ; 95 \% \mathrm{Cl}: 0.74-0.95)$. Duration of oral contraceptive use and reproductive factors, including age at menarche, age at menopause, type of menopause, ever having an abortion, parity, age at first full-term pregnancy and breastfeeding, were not associated with colorectal cancer risk.

CONCLUSION: Our findings provide limited support for a potential inverse association between oral contraceptives and colorectal cancer risk. British Journal of Cancer (2010) 103, 1755-1759. doi:I0.1038/sj.bjc.6605965 www.bjcancer.com

Published online 2 November 2010

(c) 2010 Cancer Research UK

Keywords: oral contraceptives; reproductive history; colorectal cancer; cohort study

\footnotetext{
*Correspondence: Dr KK Tsilidis; E-mail: kostas.tsilidis@ceu.ox.ac.uk

* Deceased.

Received II June 2010; revised 4 August 2010; accepted 30 September

2010 ; published online 2 November 2010
} 
Men tend to have a slightly higher incidence of colorectal cancer than women of similar age (American Cancer Society, 2007). Oestrogen has been implicated for this decreased risk in women through mechanisms that involve reduction of secondary bile acid production (McMichael and Potter, 1980; Bayerdorffer et al, 1995), reduction of circulating insulin-like growth factor-I (Campagnoli et al, 1993; Renehan et al, 2004), and protection of the oestrogen receptor gene from methylation (Issa et al, 1994).

The epidemiologic evidence for a causal link between oral contraceptives and colorectal cancer risk is equivocal. Some studies have suggested inverse associations (Potter and McMichael, 1983; Martinez et al, 1997; Fernandez et al, 1998; Nichols et al, 2005; Campbell et al, 2007; Hannaford et al, 2007; Lin et al, 2007; Kabat et al, 2008), whereas others have found no association (Weiss et al, 1981; Bostick et al, 1994; Jacobs et al, 1994; Platz et al, 1997; Troisi et al, 1997; Levi et al, 2003; Purdue et al, 2005; Dorjgochoo et al, 2009; Rosenblatt et al, 2009). A recent metaanalysis, summarising the results from 7 cohort and 11 casecontrol studies, reported a statistically significant $19 \%$ reduced risk among ever users of oral contraceptives compared with never users, although there was no clear association with increasing duration of use (Bosetti et al, 2009). No consistent association has been observed for menstrual and reproductive variables and risk of colorectal cancer (Weiss et al, 1981; Potter and McMichael, 1983; Peters et al, 1990; Wu-Williams et al, 1991; Gerhardsson de Verdier and London, 1992; Bostick et al, 1994; Jacobs et al, 1994; Kampman et al, 1997; Martinez et al, 1997; Platz et al, 1997; Talamini et al, 1998; Nichols et al, 2005; Purdue et al, 2005; Lin et al, 2007; Sakauchi, 2007; Akhter et al, 2008; Kabat et al, 2008; Rosenblatt et al, 2009), although the majority of the studies are case-control or small cohort studies with low power to study dose-response associations.

We examined the associations of oral contraceptive use and reproductive variables with colorectal cancer risk in the large European Prospective Investigation into Cancer and Nutrition (EPIC) cohort.

\section{MATERIALS AND METHODS}

Study participants included 1878 female colorectal cancer cases (1295 colon and 583 rectal cancers) and 335924 female non-cases recruited into EPIC, a prospective cohort that was established in the 1990s in 10 European countries with more than half a million participants, mostly aged 35-70 years. Incident cancer cases were identified through linkage to population cancer registries in Denmark, Italy, The Netherlands, Norway, Spain, Sweden and the UK, or with a combination of methods including linkage to health insurance records, cancer and pathology registries, and active follow-up of study participants or their next of kin in France, Germany and Greece. The colorectal cancer diagnosis was confirmed by histology for $80.2 \%$ of the cases, by clinical examination for $11.6 \%$ and the remaining $8.2 \%$ by self-report, autopsy or death certificate. Women were excluded if they had prevalent cancer at recruitment, if they did not return the baseline lifestyle questionnaire, if they never menstruated or if they had missing information on all exposure variables. Details on the cohort population, the data collection procedures and the outcome and covariate assessment methods have been described in detail elsewhere (Riboli et al, 2002; Tsilidis et al, 2010).

Women were asked at the baseline questionnaire whether they had ever used oral contraceptives, their duration of use, and age they started use. Information on age at menarche and menopause, numbers of full-term pregnancies (live and still births) and induced or spontaneous abortions, age at the first full-term pregnancy, and the reason for menopause (natural $v s$ surgical) was also collected. Information on breastfeeding was collected for the first three full-term pregnancies and the last one. Menopausal status was defined according to information on menstruation status and ovariectomy, details of which are provided elsewhere (Dossus et al., 2010).

Hazard ratios (HR) and their 95\% confidence intervals (95\% CI) for colorectal cancer were estimated using Cox proportional hazards models stratified by EPIC-participating center and age at recruitment $(\leqslant 50,51-53,54-56,57-59,60-62,63-65,>65$ years) and adjusted for smoking status (never, former and current), self-reported diabetes mellitus (no or yes), body mass index (BMI; $<25, \geqslant 25-<30, \geqslant 30 \mathrm{~kg} \mathrm{~m}^{-2}$ ), physical activity (inactive, moderately inactive, moderately active, active, and alcohol intake (quartiles: $<0.58, \geqslant 0.58-<3.61, \geqslant 3.61-<11.08$, $\geqslant 11.08 \mathrm{~g}$ per day). Missing values for smoking status $(2.2 \%)$, diabetes (4.2\%), physical activity (13.4\%) and alcohol (0.8\%) were included as a separate category in the models. An analysis that excluded women with missing values for these covariates provided very similar results, and these are not presented here. Further adjustment for menopausal hormone therapy, waist and hip circumference, waist to hip ratio, dietary variables (intakes of energy, saturated fat, fibre, folate, calcium and red meat) or mutual adjustment for oral contraceptive use and reproductive factors in relevant models gave virtually identical results. Analyses were also performed according to EPIC country, cancer subsite (colon $v s$ rectum) and potentially modifying factors (age at recruitment (at the median, $<51 v s \geqslant 51$ years), BMI $\left(<25 v s \geqslant 25 \mathrm{~kg} \mathrm{~m}^{-2}\right)$, menopausal hormone therapy (ever $v s$ never) and menopausal status (post- $v s$ pre-/peri-menopausal)).

\section{RESULTS}

The mean ages at recruitment and diagnosis for the colorectal cancer cases were 57 and 63 years, respectively, and the mean length of follow-up in the whole cohort was 9 years. Compared

Table I Participant characteristics at recruitment among women in the European Prospective Investigation into Cancer and Nutrition cohort

\begin{tabular}{|c|c|c|}
\hline Characteristic & $\begin{array}{l}\text { Colorectal cancer } \\
\text { cases }(n=1878)\end{array}$ & $\begin{array}{c}\text { Non-cases } \\
(n=335924)\end{array}$ \\
\hline Mean (s.d.) age at recruitment (years) & $57.4(8.0)$ & $50.5(9.7)$ \\
\hline Mean (s.d.) body mass index $\left(\mathrm{kg} \mathrm{m}^{-2}\right)$ & $25.5(4.5)$ & $25.0(4.5)$ \\
\hline $\begin{array}{l}\text { Mean (s.d.) alcohol intake } \\
(\text { g per day) })^{\mathrm{a}}\end{array}$ & $10(13.7)$ & $9.0(12.2)$ \\
\hline Moderately active/active (\%) & 31.7 & 34.2 \\
\hline Current smokers (\%) & 18.5 & 19.6 \\
\hline Self-reported diabetes mellitus (\%) & 3.0 & 2.3 \\
\hline \multicolumn{3}{|l|}{ Menopausal status (\%) } \\
\hline Pre-menopausal & 11.2 & 34.2 \\
\hline Peri-menopausal/unknown & 14.7 & 18.8 \\
\hline Post-menopausal (natural/surgical) & 74.1 & 47.0 \\
\hline Ever oral contraceptive use (\%) & 43.8 & 58.4 \\
\hline $\begin{array}{l}\text { Mean (s.d.) duration of oral } \\
\text { contraceptive use (years) }\end{array}$ & $9.2(9.8)$ & $8.7(9.3)$ \\
\hline Mean (s.d.) age at menarche (years) & | $3.2(1.6)$ & |3.| (1.5) \\
\hline Mean (s.d.) age at menopause (years) ${ }^{c}$ & $49.1(4.9)$ & $48.6(5.1)$ \\
\hline Ever had a full-term pregnancy (\%) & 83.5 & 79.6 \\
\hline $\begin{array}{l}\text { Mean (s.d.) number of full-term } \\
\text { pregnancies }^{d}\end{array}$ & $2.4(1.1)$ & $2.3(1.0)$ \\
\hline $\begin{array}{l}\text { Mean (s.d.) age at first full-term } \\
\text { pregnancy, years }^{d}\end{array}$ & $25.0(4.4)$ & $24.8(4.4)$ \\
\hline Ever breastfed $(\%)^{d}$ & 81.2 & 81.8 \\
\hline
\end{tabular}

${ }^{a}$ Among consumers only; $8.8 \%$ of the cases and $9.2 \%$ of the non-cases were non-consumers of alcohol. b Among ever oral contraceptive users only. 'Among post-menopausal women only. ${ }^{\mathrm{d} A m o n g}$ women with a full-term pregnancy only. 
Table 2 Hazard ratio (HR) and 95\% confidence interval (Cl) for oral contraceptive use, reproductive variables and colorectal cancer among women in the European Prospective Investigation into Cancer and Nutrition cohort

\begin{tabular}{|c|c|c|c|}
\hline Variable & Number of cases/non-cases ${ }^{a}$ & Age and center-stratified, HR $(95 \% \mathrm{Cl})$ & Multivariable adjusted, HR ( 9 \\
\hline \multicolumn{4}{|c|}{ Oral contraceptive use } \\
\hline Never & $1040 / 138359$ & 1.00 (reference) & 1.00 (reference) \\
\hline Ever & $822 / 196040$ & $0.93(0.84-1.03)$ & $0.92(0.83-1.02)$ \\
\hline \multicolumn{4}{|c|}{ Oral contraceptive use (among post-menopausal women) } \\
\hline Never & $908 / 89064$ & 1.00 (reference) & 1.00 (reference) \\
\hline Ever & $469 / 67757$ & $0.85(0.75-0.96)$ & $0.84(0.74-0.95)$ \\
\hline \multicolumn{4}{|c|}{ Oral contraceptive use (among pre-/peri-menopausal women) } \\
\hline Never & $132 / 49295$ & 1.00 (reference) & 1.00 (reference) \\
\hline Ever & $353 / 128283$ & $1.22(0.99-1.51)$ & $1.19(0.96-1.48)$ \\
\hline P-interaction & & $<0.01$ & $<0.01$ \\
\hline \multicolumn{4}{|c|}{ Duration of oral contraceptive use (years) ${ }^{c}$} \\
\hline$\leqslant 1$ & $161 / 36175$ & 1.00 (reference) & 1.00 (reference) \\
\hline $2-4$ & $167 / 42208$ & $0.99(0.80-1.24)$ & $0.99(0.80-1.23)$ \\
\hline $5-9$ & $150 / 42409$ & $0.94(0.75-1.18)$ & $0.93(0.74-1.17)$ \\
\hline$\geqslant 10$ & $264 / 58041$ & $1.10(0.90-1.36)$ & $1.09(0.89-1.35)$ \\
\hline$P$-trend & & 0.37 & 0.41 \\
\hline \multicolumn{4}{|l|}{ Age at menarche } \\
\hline$<12$ & $258 / 49935$ & 1.00 (reference) & 1.00 (reference) \\
\hline 12 & $358 / 70982$ & $0.95(0.81-1.11)$ & $0.95(0.81-1.12)$ \\
\hline 13 & $457 / 85998$ & $0.96(0.83-1.12)$ & $0.97(0.84-1.14)$ \\
\hline 14 & $424 / 71912$ & $0.95(0.82-1.12)$ & $0.97(0.83-1.14)$ \\
\hline$\geqslant 15$ & $352 / 52954$ & $0.95(0.80-1.12)$ & $0.96(0.82-1.14)$ \\
\hline$P$-trend & & 0.64 & 0.80 \\
\hline \multicolumn{4}{|c|}{ Age at menopause ${ }^{d}$} \\
\hline$\leqslant 50$ & $654 / 77482$ & 1.00 (reference) & 1.00 (reference) \\
\hline $51-52$ & $200 / 20489$ & $1.06(0.90-1.25)$ & $1.07(0.91-1.25)$ \\
\hline $53-55$ & $196 / 18391$ & $1.06(0.90-1.25)$ & $1.07(0.91-1.26)$ \\
\hline$>55$ & $59 / 5084$ & $0.99(0.76-1.30)$ & $1.00(0.76-1.31)$ \\
\hline$P$-trend & & 0.58 & 0.54 \\
\hline \multicolumn{4}{|c|}{ Type of menopause ${ }^{d}$} \\
\hline Natural & |303/147920 & 1.00 (reference) & I.00 (reference) \\
\hline Surgical & $88 / 9875$ & $1.14(0.91-1.42)$ & $1.13(0.91-1.41)$ \\
\hline \multicolumn{4}{|c|}{ Induced or spontaneous abortion } \\
\hline Never & $1129 / 180995$ & 1.00 (reference) & 1.00 (reference) \\
\hline Ever & $221 / 45509$ & $1.01(0.87-1.18)$ & $1.00(0.86-1.17)$ \\
\hline \multicolumn{4}{|c|}{ Full-term pregnancy } \\
\hline Never & $231 / 49342$ & 1.00 (reference) & 1.00 (reference) \\
\hline Ever & $1568 / 267467$ & $0.96(0.83-1.10)$ & $0.96(0.83-1.10)$ \\
\hline \multicolumn{4}{|c|}{ Number of full-term pregnancies ${ }^{\mathrm{e}}$} \\
\hline I & $250 / 49177$ & 1.00 (reference) & 1.00 (reference) \\
\hline 2 & $721 / 129409$ & $1.16(1.00-1.34))$ & $1.16(1.01-1.35)$ \\
\hline 3 & $384 / 61490$ & $1.15(0.98-1.36)$ & $1.16(0.98-1.36)$ \\
\hline$\geqslant 4$ & $213 / 27391$ & $1.17(0.97-1.41)$ & $1.17(0.97-1.42)$ \\
\hline$P$-trend & & 0.15 & 0.15 \\
\hline \multicolumn{4}{|c|}{ Age at first full-term pregnancy ${ }^{\mathrm{e}}$} \\
\hline$\leqslant 20$ & $210 / 40007$ & 1.00 (reference) & I.00 (reference) \\
\hline $21-23$ & $433 / 71912$ & $1.01(0.86-1.19)$ & $1.02(0.86-1.21)$ \\
\hline $24-25$ & $320 / 52140$ & $0.97(0.81-1.16)$ & $0.98(0.82-1.18)$ \\
\hline $26-30$ & $439 / 75488$ & $0.90(0.76-1.07)$ & $0.92(0.77-1.09)$ \\
\hline$>30$ & $163 / 26886$ & $0.98(0.79-1.20)$ & $0.99(0.80-1.22)$ \\
\hline P-trend & & 0.22 & 0.30 \\
\hline \multicolumn{4}{|l|}{ Breastfeeding ${ }^{e}$} \\
\hline Never & $211 / 39471$ & 1.00 (reference) & I.00 (reference) \\
\hline Ever & $1273 / 218695$ & $1.12(0.97-1.31)$ & $1.13(0.97-1.32)$ \\
\hline
\end{tabular}

The number of cases and non-cases do not add up to the total number of 1878 cases and 335924 non-cases because of missing values. ${ }^{b}$ From a Cox proportional hazards model stratified by the European Prospective Investigation into Cancer and Nutrition participating center and age at recruitment, and adjusted for smoking status (never, former, current), diabetes mellitus (never, ever), body mass index $\left(<25, \geqslant 25-<30, \geqslant 30 \mathrm{~kg} \mathrm{~m}^{-2}\right)$, physical activity (inactive, moderately inactive, moderately active, active), and alcohol use $(<0.58$, $\geqslant 0.58-<3.61, \geqslant 3.61-<11.08, \geqslant 11.08 \mathrm{~g}$ per day). ${ }^{C}$ Among ever oral contraceptive users only. ${ }^{\mathrm{C}}$ Among post-menopausal women only. ${ }^{\mathrm{e}}$ Among women with a full-term pregnancy. 
with women without colorectal cancer, cases were on average older, had slightly higher BMI, drank more alcohol, exercised less and were less likely to have ever taken oral contraceptives (Table 1).

Overall, there were no statistically significant associations between oral contraceptives, reproductive factors and colorectal cancer risk (Table 2). Ever use of oral contraceptives was marginally inversely associated with risk (HR, 0.92; 95\% CI: $0.83-1.02$ ), but neither duration of use ( $P$-trend, 0.41$)$ nor age at start of use ( $P$-trend, 0.32) were associated with risk. However, the association of oral contraceptive use on risk varied by menopausal status ( $P$-interaction, $<0.01$ ); ever use of oral contraceptives was associated with a significantly reduced risk in post-menopausal women (HR, $0.84 ; 95 \% \mathrm{CI}$ : $0.74-0.95$ ), but no significant association was observed among pre- or peri-menopausal women (HR, 1.19; 95\% CI: 0.96-1.48). There was no evidence of an interaction for duration or age at start of oral contraceptive use by menopausal status (data not shown).

Reproductive factors, including age at menarche, age at menopause, type of menopause, ever having an abortion, parity, age at first full-term pregnancy and breastfeeding, were not associated with colorectal cancer risk (Table 2). The associations between oral contraceptive use, reproductive factors and colorectal cancer risk did not differ according to country, colorectal cancer subsite and baseline characteristics (age, BMI, menopausal hormone therapy and menopausal status).

\section{DISCUSSION}

In this large prospective study, ever use of oral contraceptives was associated with a small reduction in colorectal cancer risk, which was stronger among post-menopausal women compared with pre-/peri-menopausal women. Although our finding of an inverse association with use of oral contraceptives is consistent with the prior literature (Bosetti et al, 2009), most studies have not reported a reduction in colorectal cancer risk with increasing duration of oral contraceptive use (Bosetti et al, 2009). This may, in part, be because of relatively small study sizes to detect a significant association, although the present study, with over 1800 cases, also found no association with duration of oral contraceptive use. Our stronger inverse finding for oral contraceptive use and colorectal cancer risk in post-menopausal women did not change after adjustment for menopausal hormone therapy and reproductive variables, and is not explained by a longer duration of oral contraceptive use among older women as there was no association between duration of use and risk overall or in subgroups by menopausal status. In addition, post-menopausal women had only a slightly longer mean duration of oral contraceptive use compared with pre-/peri-menopausal women (9.1 vs 8.5 years), despite being older at recruitment (58 vs 44 years). However, post-menopausal women were more likely to have started using oral contraceptives during the $1960 \mathrm{~s}$ when high-dose formulations were much more common (McMichael and Potter, 1980), which may partly explain the apparent higher risk in these women. Earlier studies have not reported significant interactions between oral contraceptive use and colorectal cancer risk by age or menopausal status (Kampman et al, 1997; Lin et al, 2007); however, one case-control study observed a non-significant reduced risk of colon cancer for ever use of oral contraceptives among women older than 62 years at recruitment, and no association among younger women (Kampman et al, 1997). Future studies with detailed information on the dose and hormonal constituent of the oral contraceptives are needed to clarify this association. No significant associations were found for reproductive factors, which is consistent with most of the literature (Gerhardsson de Verdier and London, 1992; Kampman et al, 1997; Troisi et al, 1997; Nichols et al, 2005; Lin et al, 2007; Sakauchi, 2007; Akhter et al, 2008; Kabat et al, 2008).

The major strength of this study is its size and power to study dose-response associations, and its detailed and standardised assessment of reproductive factors across Europe. In conclusion, oral contraceptive use was associated with a reduced risk of colorectal cancer among post-menopausal women. Duration of oral contraceptive use and reproductive factors were not associated with risk. Our findings provide limited support for a potential inverse association between oral contraceptives and colorectal cancer risk.

\section{ACKNOWLEDGEMENTS}

The coordination of EPIC is financially supported by the European Commission (DG-SANCO) and the International Agency for Research on Cancer. The national cohorts are supported by Danish Cancer Society (Denmark); Ligue contre le Cancer, Société $3 \mathrm{M}$, Mutuelle Générale de l'Education Nationale, Institut National de la Santé et de la Recherche Medicale (France); Deutsche Krebshilfe, Deutsches Krebsforschungszentrum and Federal Ministry of Education and Research (Germany); Ministry of Health and Social Solidarity, Stavros Niarchos Foundation and Hellenic Health Foundation (Greece); Italian Association for Research on Cancer (AIRC) and National Research Council (Italy); Dutch Ministry of Public Health, Welfare and Sports (VWS), Netherlands Cancer Registry (NKR), LK Research Funds, Dutch Prevention Funds, Dutch ZON (Zorg Onderzoek Nederland), World Cancer Research Fund (WCRF); Statistics Netherlands(The Netherlands); Norwegian Cancer Society (Norway); Health Research Fund (FIS), Regional Governments of Andalucía, Asturias, Basque Country, Murcia and Navarra, ISCIII RETIC (RD06/0020) (Spain); Swedish Cancer Society, Swedish Scientific Council and Regional Government of Skåne and Västerbotten (Sweden); Cancer Research UK, Medical Research Council, Stroke Association, British Heart Foundation, Department of Health, Food Standards Agency, and Wellcome Trust (United Kingdom).

\section{REFERENCES}

Akhter M, Inoue M, Kurahashi N, Iwasaki M, Sasazuki S, Tsugane S (2008) Reproductive factors, exogenous female hormone use and colorectal cancer risk: the Japan Public Health Center-based Prospective Study. Eur J Cancer Prev 17: 515-524

American Cancer Society (2007) Global Cancer Facts and Figures 2007. American Cancer Society: Atlanta

Bayerdorffer E, Mannes GA, Ochsenkuhn T, Dirschedl P, Wiebecke B, Paumgartner G (1995) Unconjugated secondary bile acids in the serum of patients with colorectal adenomas. Gut 36: $268-273$
Bosetti C, Bravi F, Negri E, La Vecchia C (2009) Oral contraceptives and colorectal cancer risk: a systematic review and meta-analysis. Hum Reprod Update 15: 489-498

Bostick RM, Potter JD, Kushi LH, Sellers TA, Steinmetz KA, McKenzie DR, Gapstur SM, Folsom AR (1994) Sugar, meat, and fat intake, and nondietary risk factors for colon cancer incidence in Iowa women (United States). Cancer Causes Control 5: 38-52

Campagnoli C, Biglia N, Altare F, Lanza MG, Lesca L, Cantamessa C, Peris C, Fiorucci GC, Sismondi P (1993) Differential effects of oral conjugated 
estrogens and transdermal estradiol on insulin-like growth factor 1, growth hormone and sex hormone binding globulin serum levels. Gynecol Endocrinol 7: 251-258

Campbell PT, Newcomb P, Gallinger S, Cotterchio M, McLaughlin JR (2007) Exogenous hormones and colorectal cancer risk in Canada: associations stratified by clinically defined familial risk of cancer. Cancer Causes Control 18: $723-733$

Dorjgochoo T, Shu XO, Li HL, Qian HZ, Yang G, Cai H, Gao YT, Zheng W (2009) Use of oral contraceptives, intrauterine devices and tubal sterilization and cancer risk in a large prospective study, from 1996 to 2006. Int J Cancer 124: 2442-2449

Dossus L, Allen N, Kaaks R, Bakken K, Lund E, Tjonneland A, Olsen A, Overvad K, Clavel-Chapelon F, Fournier A, Chabbert-Buffet N, Boeing H, Schutze M, Trichopoulou A, Trichopoulos D, Lagiou P, Palli D, Krogh V, Tumino R, Vineis P, Mattiello A, Bueno-de-Mesquita HB, Onland-Moret NC, Peeters PH, Dumeaux V, Redondo ML, Duell E, Sanchez-Cantalejo E, Arriola L, Chirlaque MD, Ardanaz E, Manjer J, Borgquist S, Lukanova A, Lundin E, Khaw KT, Wareham N, Key T, Chajes V, Rinaldi S, Slimani N, Mouw T, Gallo V, Riboli E (2010) Reproductive risk factors and endometrial cancer: the European Prospective Investigation into Cancer and Nutrition. Int J Cancer 127: 442-451

Fernandez E, La Vecchia C, Franceschi S, Braga C, Talamini R, Negri E, Parazzini F (1998) Oral contraceptive use and risk of colorectal cancer. Epidemiology 9: 295-300

Gerhardsson de Verdier M, London S (1992) Reproductive factors, exogenous female hormones, and colorectal cancer by subsite. Cancer Causes Control 3: $355-360$

Hannaford PC, Selvaraj S, Elliott AM, Angus V, Iversen L, Lee AJ (2007) Cancer risk among users of oral contraceptives: cohort data from the Royal College of General Practitioner's oral contraception study. BMJ 335: 651

Issa JP, Ottaviano YL, Celano P, Hamilton SR, Davidson NE, Baylin SB (1994) Methylation of the oestrogen receptor CpG island links ageing and neoplasia in human colon. Nat Genet 7: $536-540$

Jacobs EJ, White E, Weiss NS (1994) Exogenous hormones, reproductive history, and colon cancer (Seattle, Washington, USA). Cancer Causes Control 5: 359-366

Kabat GC, Miller AB, Rohan TE (2008) Oral contraceptive use, hormone replacement therapy, reproductive history and risk of colorectal cancer in women. Int $J$ Cancer 122: 643-646

Kampman E, Potter JD, Slattery ML, Caan BJ, Edwards S (1997) Hormone replacement therapy, reproductive history, and colon cancer: a multicenter, case-control study in the United States. Cancer Causes Control 8: 146-158

Levi F, Pasche C, Lucchini F, La Vecchia C (2003) Oral contraceptives and colorectal cancer. Dig Liver Dis 35: 85-87

Lin J, Zhang SM, Cook NR, Manson JE, Buring JE, Lee IM (2007) Oral contraceptives, reproductive factors, and risk of colorectal cancer among women in a prospective cohort study. Am J Epidemiol 165: 794-801

Martinez ME, Grodstein F, Giovannucci E, Colditz GA, Speizer FE, Hennekens C, Rosner B, Willett WC, Stampfer MJ (1997) A prospective study of reproductive factors, oral contraceptive use, and risk of colorectal cancer. Cancer Epidemiol Biomarkers Prev 6: 1-5

McMichael AJ, Potter JD (1980) Reproduction, endogenous and exogenous sex hormones, and colon cancer: a review and hypothesis. J Natl Cancer Inst 65: $1201-1207$

Nichols HB, Trentham-Dietz A, Hampton JM, Newcomb PA (2005) Oral contraceptive use, reproductive factors, and colorectal cancer risk: findings from Wisconsin. Cancer Epidemiol Biomarkers Prev 14: 1212-1218
Peters RK, Pike MC, Chang WW, Mack TM (1990) Reproductive factors and colon cancers. Br J Cancer 61: 741-748

Platz EA, Martinez ME, Grodstein F, Fuchs CS, Colditz GA, Stampfer MJ, Giovannucci E (1997) Parity and other reproductive factors and risk of adenomatous polyps of the distal colorectum (United States). Cancer Causes Control 8: 894-903

Potter JD, McMichael AJ (1983) Large bowel cancer in women in relation to reproductive and hormonal factors: a case-control study. J Natl Cancer Inst 71: $703-709$

Purdue MP, Mink PJ, Hartge P, Huang WY, Buys S, Hayes RB (2005) Hormone replacement therapy, reproductive history, and colorectal adenomas: data from the prostate, lung, colorectal and ovarian (PLCO) cancer screening trial (United States). Cancer Causes Control 16: $965-973$

Renehan AG, Zwahlen M, Minder C, O'Dwyer ST, Shalet SM, Egger M (2004) Insulin-like growth factor (IGF)-I, IGF binding protein-3, and cancer risk: systematic review and meta-regression analysis. Lancet 363: $1346-1353$

Riboli E, Hunt KJ, Slimani N, Ferrari P, Norat T, Fahey M, Charrondiere UR, Hemon B, Casagrande C, Vignat J, Overvad K, Tjonneland A, ClavelChapelon F, Thiebaut A, Wahrendorf J, Boeing H, Trichopoulos D, Trichopoulou A, Vineis P, Palli D, Bueno-De-Mesquita HB, Peeters PH, Lund E, Engeset D, Gonzalez CA, Barricarte A, Berglund G, Hallmans G, Day NE, Key TJ, Kaaks R, Saracci R (2002) European Prospective Investigation into Cancer and Nutrition (EPIC): study populations and data collection. Public Health Nutr 5: 1113-1124

Rosenblatt KA, Gao DL, Ray RM, Nelson ZC, Wernli KJ, Li W, Thomas DB (2009) Oral contraceptives and the risk of all cancers combined and site-specific cancers in Shanghai. Cancer Causes Control 20: $27-34$

Sakauchi F (2007) Reproductive history and health screening for women and mortality in the Japan Collaborative Cohort Study for Evaluation of Cancer (JACC). Asian Pac J Cancer Prev 8( Suppl): 129-134

Talamini R, Franceschi S, Dal Maso L, Negri E, Conti E, Filiberti R, Montella M, Nanni O, La Vecchia C (1998) The influence of reproductive and hormonal factors on the risk of colon and rectal cancer in women. Eur J Cancer 34: 1070-1076

Troisi R, Schairer C, Chow WH, Schatzkin A, Brinton LA, Fraumeni Jr JF (1997) Reproductive factors, oral contraceptive use, and risk of colorectal cancer. Epidemiology 8: 75-79

Tsilidis KK, Allen NE, Key TJ, SanJoaquin MA, Bakken K, Berrino F, Fournier A, Lund E, Overvad K, Olsen A, Tjønneland A, Byrnes G, Chajes V, Rinaldi S, Boutron-Ruault M-C, Clavel-Chapelon F, Chang-Claude J, Kaaks R, Bergmann M, Boeing H, Koumantaki Y, Palli D, Pala V, Panico S, Tumino R, Vineis P, Bueno-de-Mesquita HB, van Duijnhoven FJB, van Gils $\mathrm{CH}$, Peeters PHM, Rodríguez L, González CA, Sánchez M-J, Chirlaque M-D, Barricarte A, Dorronsoro M, Khaw K-T, Rodwell SA, Norat T, Romaguera D, Riboli E (2010) Menopausal hormone therapy and risk of colorectal cancer in the European Prospective Investigation into Cancer and Nutrition. Int J Cancer (accepted)

Weiss NS, Daling JR, Chow WH (1981) Incidence of cancer of the large bowel in women in relation to reproductive and hormonal factors. J Natl Cancer Inst 67: 57-60

Wu-Williams AH, Lee M, Whittemore AS, Gallagher RP, Jiao DA, Zheng S, Zhou L, Wang XH, Chen K, Jung D, Teh C-Z, Chengde L, Yao XJ, Paffenbarger RS, Henderson BE (1991) Reproductive factors and colorectal cancer risk among Chinese females. Cancer Res 51: 2307-2311 